\title{
COMUNICAÇÕES
}

\section{AUTO-IMUNIDADE NÃO É IMPEDITIVO PARA VACINAÇÃO CONTRA DOENÇA DE CHAGAS}

\author{
Antônio R.L. Teixeira, Edécio Cunha Neto e Luiz Vicente Rizzo
}

\begin{abstract}
As pessoas normalmente não reagem contra seus próprios tecidos, a não ser que as células imunocompetentes possam tornar-se sensibilizadas contra seus componentes próprios, por imunógenos que, embora possuindo estruturas dissimilares, tenham em comum um epitopo particular ${ }^{28}$, ou se o componente próprio pode ser modificado (haptenizado) pelo imunógeno ${ }^{14}$. Linfócitos $\mathrm{T}$ citotóxicos de humanos ou de roedores reconhecem determinantes antigênicos estranhos associados com os produtos do complexo maior de histocompatibilidade (MHC). Este, porém, não parece ser o caso da doença de Chagas onde as lesões são órgão ou estruturasespecificas, enquanto que os antígenos de histocompatibilidade (HLA, H2) estão presentes em todas as células nucleadas do corpo. Ademais, já é conhecido que determinantes antigênicos próprios, não associados ao MHC, podem estar envolvidos na geração de reaçōes citotóxicas contra os componentes próprios ${ }^{14}$.
\end{abstract}

\section{Características gerais de doença auto-imune}

As evidências indicam que a enorme complexidade antigênica do Trypanosoma cruzi, variando durante seu ciclo de vida, pode ser responsável pela indução de grande variedade de respostas imunes no hospedeiro vertebrado, algumas das quais dirigidas contra componentes próprios (células cardíacas e neurônios parassimpáticos), não necessariamente sob restrição do MHC. Algumas dessas evidências, que são usadas como argumentos para indicar a provável autoimunidade associada com a doença de Chagas, também estão presentes, similarmente, em outras doenças auto-anticorpos reativos contra múltiplos componennas doenças auto-imunes (p. ex. tireoidite de Hashimoto, artrite reumatóide, lupus eritematoso) a presença de auto-anticorpos reativos contra múltiplos componentes teciduais. A doença de Chagas não faz exceção à regra. Assim, já foram descritos anticorpos reativos contra musculatura estriada cardiaca e esquelética ${ }^{22}$, contra neurônios simpáticos e parassimpáticos ${ }^{11}$, contra endotélio e estruturas vasculares ${ }^{6}$, contra nervo periférico ${ }^{22} \mathrm{e}$ contra laminina ${ }^{20} \mathrm{e}$, ainda, anticorpos antinucleares e fatores reumatóides. Tal fator reuma-

Laboratório de Imunopatologia/MDC, Faculdade de Ciências da Saúde, Universidade de Brasília, Brasilia, DF. Recebido para publicação em 18/12/85. tóide foi identificado como imunoglobulina $\mathrm{M}$ altamente reativa com gamaglobulina, $o$ que sugere que ele seja verdadeiro auto-anticorpo ${ }^{35}$. De maior interesse, vários desses anticorpos reativos com estruturas próprias podem ser absorvidos com formas de $T$. cruz $i$. A propósito do argumento de Kierszenbaum ${ }^{9}$, no que se refere ao anticorpo antilaminina, nào os pareceu lícito pinçar aquele trabalho cientifico, que mostra reação imunológica cruzada contra autoconstituintes, e colocá-lo sob suspeita com base na necessidade de "confirmação do achado por outros autores", pois, essa premissa é válida para todo trabalho científico, sem exceção.

\section{Genes de auto-imunidade}

Seria mais interessante, pois, discutir aqui a associação entre os genes de auto-imunidade e o agravamento do curso da infecção pelo $T$. cruzi, que foi demonstrado em raças de camundongos congênicos suscetíveis a doenças auto-imunes. Em um desses estudos ${ }^{1}$, verificou-se que uma aberração auto-imune subjacente pode contribuir para as consequiências imunopatológicas da doença de Chagas. Verificou-se que quatro cepas de camundongos possuidoras de gene autossômico recessivo (lpr), que controle a linfoproliferação e algumas manifestações auto-imunes, foram altamente suscetiveis às infecçōes pelo $T$. $c r u z i{ }^{1}$. Demonstrou-se também que camundongos das cepas BXSB e NZB são altamente suscetiveis ao desenvolvimento de doenças auto-imunes e de infecções severas pelo $T$. cruzi ${ }^{15}$. Camundongos BXSB machos (BXSC - Y ${ }^{\text {sb }}$ ), que têm doença auto-imune precocemente, tiveram mortalidade aumentada. Todavia, as fêmeas BXSC, que só tem doença auto-imune tardiamente, puderam se recuperar de infecçōes com tripanossomos virulentos ${ }^{15}$. Fenômeno similar foi observado com camundongos NZB, que são altamente suscetiveis ao T. cruzi, enquanto os animais NZW e $\mathrm{NZB} / \mathrm{W}$ são resistentes ${ }^{15}$. Esses dados mostram que animais homozigotos para genes autossômicos recessivos associados a auto-imunidade têm maior suscetibilidade às infecções pelo $T$. cruzi que os animais congênicos sem o gene de suscetibilidade, ou heterozigotos, o que pode sugerir defeito do controle regulador da reatividade imunológica e da discriminação próprio não-próprio nesses animais. 


\section{Auto-imunidade na doença de Chagas}

Observou-se que o $T$. cruzi que emerge após a replicação intracelular adquire caracteristicas da membrana da célula hospedeira, mas esta aquisiçâo é reversivel, devido à deleção ou endocitose dessas substâncias ${ }^{4}$. Em contraste, observou-se também ligação de antígenos do parasito à membrana da célula hospedeira ${ }^{16}$. Esta observação pode explicar a rejeição da célula hospedeira por linfócitos imunocompetentes $^{17}$. A localização de antígenos na membrana de células musculares e de neurônios parasitados pelo $T$. cruzi faz com que essas células sejam alvo da lise imunológica ${ }^{17}$. A destruição imune de células-alvo parasitadas pode estar relacionada a este mecanismo, que representa uma reação auto-imune ameaçadora nos corações de indivíduos com a infecção aguda, podendo destruir muitas miofibras e levar à insuficiência cardiaca.

Outras observações mostraram que linfócitos imunes aderem e lesam células cardiacas de coelhos ou humanos, parasitados e não-parasitados, in vitro 71823 . A liberação de $\mathrm{Cr}^{51}$ de células cardiacas fetais humanas foi mediada por linfócitos $\mathbf{T}$ de pacientes com doença de Chagas ${ }^{18}$. $\mathrm{O}$ grau de órgão especificidade da reação citotóxica antimiocárdio foi indicado pelo fato de que os linfócitos imunes ao $T$. cruzi não destruíram células renais ${ }^{18}$ ou hepáticas 23 homólogas. A crítica ${ }^{9}$ esqueceu de mencionar o real significado desses controles. Embora F. Kierszenbaum $^{9}$ não questione a significância estatística das diferenças de liberação de $\mathrm{Cr}^{51}$ das células cardíacas, nos experimentos testes e controles, ele chamou a atenção para a "grande liberação de $\mathrm{Cr}^{51}$ produzida por linfócitos dos controles não chagásicos". Todavia, a crítica não considerou o fato de que no protocolo empregado a liberação espontânea de $\mathrm{Cr}^{51}$, que sempre está presente nesses experimentos, não foi subtraída dos valores das cpm de cada experimento, o que ajudaria a embelezar esses resultados. Optou-se pela apresentação dos dados sem disfarces. Adicionalmente, observou-se que a aderência de linfócitos $\mathbf{T}$ imunes, obtidos de coelhos isogênicos infectados com $T$. cruzi, contra células cardíacas isólogas em cultura resultou na cessação das pulsações ${ }^{24}$. Não é possível que tal reação citotóxica, observada com apenas 1 hora de incubação, seja devida à sensibilização in vitro, contra antigenos de histocompatibilidade, pois a sensibilização aos aloantígenos requer pelo menos 72 horas para acontecer.

\section{Base da auto-imunidade: determinantes antigênicos comuns}

Há também de se considerar aqui a tese ${ }^{9}$ de que "a auto-imunidade na doença de Chagas seria subse- qüente à produção de lesões chagásicas", resultantes da exposição do sistema imune a antígenos previamente abrigados ou de tecidos modificados. Neste ponto, o próprio questionador já admite a existência de certo tipo preferencial de auto-imunidade na doença de Chagas. A este respeito, convém lembrar resultados de experimentos que mostram reatividade cruzada entre anticorpos do soro de coelhos chagásicos e músculo cardíaco. Pelo teste de imunofluorescência indireta esses anticorpos coravam o sarcolema e também o citoplasma das fibras cardíacas ${ }^{22}$. Só foi possivel absorver apenas parcialmente esses anticorpos com sobrenadantes de homogeneizados de músculo cardiaco, porém foi obtida a absorção total com homogeneizado de formas de cultura do $T$. cruzi ${ }^{22}$ crescidas em ágar-sangue. Recentemente, demonstrou-se a presença de um anticorpo sérico contra um poliperptídeo de $25 \mathrm{kd}$ do $T$. cruzi, em $94,1 \%$ dos pacientes com cardiomiopatia avançada. Esse anticorpo IgG tem grande avidez anti-sarcolema da fibra cardiaca ${ }^{19}$. Similarmente, um anticorpo que reage com bainha de Schwann de nervos periféricos autônomos foi encontrado em 85 por cento dos soros chagásicos examinados. Esses anticorpos também foram absorvidos com formas de T. cruzi liofilizadas ${ }^{11}$. Ademais, um antígeno microssomal de células cardíacas pode inibir a migração de células monocelulares de coelhos infectados com $T$. cruzi ${ }^{18}$. Resultados similares foram descritos em infecções murinas e humanas pelo $T$. cruzi ${ }^{1325}$. Esse conjunto de observações indica a presença de determinante antigênico comum ao $T$. cruzi e a fibra cardiaca, ou certas células alvo dos hospedeiro.

\section{Patogênese}

A gênese das lesões da doença de Chagas era creditada tão-somente à ação das formas intracelulares do parasito. A inflamação severa que é característica da cardiomiopatia chagásica era considerada como resultante da ação de produtos "tóxicos", liberados após a rutura dos pseudocistos contendo as formas de T. cruzi. Contudo, essa moçãojá se chocava com as primeiras descrições que se referiam ao parasitismo quiescente das células, contrastando com as lesões inflamatórias, associadas ao infiltrado linfocitário, em que os parasitos não são encontrados. As evidências da associação in vitro entre linfócitos imunes e célula cardíaca foram encontradas também nas biópsias de miocárdio, em que interação íntima entre a célula efetora e a célula-alvo resultava na imbricação das membranas plasmáticas, desaparecimento da lâmina basal e da membrana sarcolemal da célula-alvo, permitindo os processos citoplasmáticos efetores inserirem-se nas estruturas miofibrilares do sarcoplasma da fibra cardíaca não-parasitada ${ }^{19} 21$. 
Esses achados in vivo são idênticos àqueles observados in vitro quando se incubaram linfócitos imunes ao $T$. cruzi com células cardiacas.

Quando se examina esse conjunto de observações fica improvável que a patogênese da doença de Chagas seja relacionada à ação mecânica ou tóxica dos parasitos. Mesmo porque a antiga teoria deixa de responder a muitas questões práticas com amplas implicações na abordagem da imunoprofilaxia da doença de Chagas:

1) Porque vários mamiferos, reservatórios naturais do $\mathrm{T}$. cruzi, não adoecem em conseqüência da infecção? É notável o grau de adaptação do parasito aos animais silvestres que servem de reservatório, pois as infecções pelo $T$. cruzi não parecem prejudicá-los, enquanto ambas espécies sobrevivem em um estado de equilibrio estável, possivelmente decorrente de um processo de longa adaptação. Já se conhece que determinada coorte da população humana infectada pelo T. cruzi sobrevive à infecção sem indícios de doença e, destarte, também pode ser incluída no conceito de reservatório $T$. cruzi. A noção de reservatório é central à idéia de que nāo basta ter a infecção para ter a doença de Chagas. Esta só parece ocorrer em certa coorte de indivíduos descendentes da população européia e africana, que chegaram ao Novo Continente na era pós-Colombiana.

2) Por que as infecçôes agudas em infantes e crianças usualmente passam despercebidas e cedem espontaneamente? Se as lesões da doença de Chagas fossem produzidas pela ação direta do parasito, deveria ocorrer altos indices de morbidade e mortalidade nesta fase da infecção quando é maior o parasitismo dos tecidos. Todavia, isto nem sempre ocorre. Observouse que apenas a minoria dos individuos, portadores de infecção aguda sintomática, podiam produzir uma reação cutânea de hipersensibilidade tardia contra o antigeno microssomal do $T$. cruzi ${ }^{26}$. A grande maioria dos indivíduos com a infecção aguda, mas sem sintomas clinicos, não apresentavam qualquer reatividade imunológica que pudesse ser creditada aos linfócitos 26 . Existe, pois, a possibilidade de que as manifestações clínicas e a gravidade da enfermidade possam estar relacionadas às reaçōes de hipersensibilidade tardia contra certos antígenos do parasito, aqueles de reatividade cruzada, em individuos geneticamente predispostos.

3) Por que taxas elevadas de morbidade e mortalidade na doença de Chagas são vistas freqüentemente muitas décadas após a fase aguda da infecção? Estudos de campo demonstraram que a maior prevalência de alterações eletrocardiográficas em indivíduos portadores da infecção ocorre na terceira e quarta décadas da vida, geralmente quando os xenodiagnósticos não conseguem detectar parasitemias ${ }^{28}$. Por outro lado, um teste cutâneo de hipersensibilidade tardia contra um antigeno do $T$. cruzi produz as reações mais intensas nos indivíduos, entre 30 e 50 anos de vida, portadores da infecção. Verifica-se também na terceira e quarta décadas de vida a maior taxa de mortalidade pela doença de Chagas, exatamente quando os xenos tendem a ser negativos e as reações imunes de hipersensibilidade são mais intensas. Verificou-se, pois, uma relação negativa entre morbidade e mortalidade com a parasitemia, e uma relação positiva entre morbidade e mortalidade com as reações imunes. Isto sugere uma destruição silenciosa do miocárdio, típica de um processo auto-imune ${ }^{27}$.

4) Por que os parasitos dificilmente são encontrados in situ e não são associados às lesôes vistas em indivíduos que morrem de doença de Chagas crônica. Este aspecto das patologias da doença de Chagas é realmente singular. Não há como associar a presença do parasito com a lesão. Esta parece decorrer do estado de hipersensibilidade.

Parece que as respostas para essas perguntas não poderiam ser encontradas nos conceitos antigos, mas no exame do papel que os mecanismos imunes desempenham na modulação das interações parasito/ hospedeiro. São estes mecanismos que induzem as reações auto-imunes descritas acima. Isto ficou demonstrado também com a transferência passiva da doença cardiaca de camundongos isogênicos $\mathrm{Balb} / \mathrm{C}$, com a infecção crônica pelo $T$. cruzi, para receptores singênicos normais, através de linfócitos imunocompetentes. Infiltrado linfocitário difuso e lise da célula cardíaca foram encontrados no coração dos camundongos, dois dias após terem recebido as células $\mathbf{T}$ imunes $^{12}$.

\section{Vacina}

A maior dificuldade no que se refere ao desenvolvimento de uma vacina contra doença de Chagas está numa limitação do conhecimento cientifico, ou seja: na prática, a imunoprofilaxia contra o $T$. cruzi requer imunidade estéril, e ainda não se dispõe de meios para produzi-la. Isto quer dizer que qualquer vacina eficaz teria de induzir um estado sólido de imunidade muito mais potente do que aquele induzido pela infecção pelo $T$. cruzi $i$. Até o presente momento as tentativas de obtenção do tal superantigeno foram infrutíferas e, também, não há indícios de que ele exista. Todos os métodos convencionais de produção de vacinas ${ }^{10}$, até então experimentados, levaram à imunoproteção parcial contra a infecção aguda (humanos geralmente sobrevivem à fase aguda da infecção, mesmo sem qualquer tratamento), mas os animais vacinados continuam a exibir parasitemias e reações imunes de ampla especificidade, e, portanto, seguem 
portadores de todas as condições para o desenvolvimento da doença de Chagas crônica 27 . As dificuldades para alcançar uma vacina eficaz incluem necessariamente: 1) a imunoprofilaxia contra a doença de Chagas pode não ser alcançada através dos métodos convencionais até aqui empregados ${ }^{10}$. Novos conhecimentos precisam ser adquiridos, de forma a resolver inúmeras questões relacionadas à vacinação contra infecções crônicas; 2) certamente, o envolvimento da auto-imunidade na doença de Chagas sugere que qualquer procedimento efetivo de vacinação deve ser buscado de forma inovadora e requer muito mais trabalho nos laboratórios de pesquisa. Se for possivel seguir esta trilha, os imunologistas ficarão, seguramente, indenes à falácia de observadores putativos de fora, que acusam indevidamente: "há mais gente vivendo de doença de Chagas que morrendo dela".

\section{REFERÊNCIAS BIBLIOGRÁFICAS}

1. Boyer MH, Hoff, R, Kipnis, TL, Murphy ED, Roths JB. Trypanosoma cruzi: susceptibility in mice carrying mutant gene lpr (lymphoproliferation). Parasite Immunology 5: 135-142, 1983.

2. Castro $\mathrm{CN}$. Influência da parasitemia no quadro clínico da doença de Chagas. Tese. Faculdade de Cíências da Saúde Universidade de Brasilia p. 95, 1978.

3. Cabral, HRA. Rheumatoid factors and Chagas'disease. Science 219: 1238, 1982.

4. Chess Q, Acosta AM, Sethi JK, Santos-Buch CA. Reversible acquisition of a host cell surface membrane antigen by Trypanosoma cruzi. Infection and Immunity 40: 293-299, 1983.

5. Cossermelli W, Friedman H, Pastor H, Nobe MR, Manzione A, Camargo ME, Shiroma M. Polymyositis in Chagas'disease. Annals of Rheumatic Diseases 37: 277-283, 1978.

6. Cosio PM, Laguens RP, Diez C, Szarfman A, Segal A, Arana RM. Chagasic cardiopathy: Antibodies reacting with plasma membrane of striated muscle and endothelial cells. Circulation 50: 1252-1261, 1972.

7. Cossio PM, Damilano G, Vega MT, Laguens RP, Meckert PC, Diez C, Arana RM. In vitro interaction between lymphocytes of chagasic individuals and heart tissue. Medicina (Buenos Aires) 36: 287-295, 1976.

8. Hoff R, Mott KE, Silva JE, Menezes V, Hoff JN, Barrett TV, Sherlock I. Prevalence of parasitemia and seroreativity to Trypanosoma cruzi in a rural population of Northeast Brazil. American Joumal of Tropical Medicine and Hygiene 28: 461-473, 1979.

9. Kierszenbaum F. Auto-immunity in Chagas'disease: fact or fancy? cause or consequence? Revista da Sociedade Brasileira de Medicina Tropical 18: 129-132, 1985.

10 Kierszenbaum F, Budzko DB. Immunization against experimental Chagas'disease by using culture forms of Trypanosoma cruzi killed with a solute of sodium perchlorate. Infection and Immunity 12: 461-469, 1975.
11. Khoury EL, Ritacco V, Cossio PM, Laguens RP, Szarfman A, Diez C, Arana RM. Circulating antibodies to peripheral nerve in American trypanosomiasis (Chagas disease). Clinical and Experimental Immunology 36: 8-13, 1979.

12. Laguens RP, Meckert PC, Basombrio MA, Chambo GJ, Arana RM, Gelpi R. Infection del raton con Trypanosoma cruzi. Modelo experimental de enfermedad de Chagas. Medicina (Buenos Aires) 40: 33-38, 1980.

13. Laguens RP, Meckert PC, Chambo G, Gelpi RJ. Chronic Chagas'disease in the mouse. II Transfer of the heart disease by means of immunocompetent cells. Medicina (Buenos Aires) 41: 40-45, 1981.

14. Levy RB, Shearer GM. Can cytotoxic T cells recognize self determinants on molecules lacking polymorphic MHC self determinants? Immunology Today 3: 204, 1982.

15. Nickell SP, Hoff R, Boyer MH. Susceptibility to acute Trypanosoma cruzi infection in auto-immunestrains of mice. Parasite Immunology 7: 377-386, 1985.

16. Ribeiro dos Santos R, Hudson L. Trypanosoma cruzi: binding of parasite antigens to mammalian cell membranes. Parasite Immunology 2: 1-9, 1980.

17. Ribeiro dos Santos R, Hudson L. Trypanosoma cruzi: immunological consequences of parasite modification of host cells. Clinical and Experimental Immunology 40: 36-41, 1980.

18. Santos-Buch CA, Teixeira ARL. The immunology of experimental Chagas'disease. III. Rejection of allogenic heart cells in vitro. Journal of Experimental Medicine 140: 38-53, 1974.

19. Santos-Buch CA, Acosta AM, Zweerink HJ, Sadigursky $\mathrm{M}$, Anderson OF, von Kreuter BF, Brodskyn CI, Sadisgursky C, Cody RJ. Primary muscle disease: Definition of a 25 -kda polypeptide myopathic specific Chagas antigen. Clinical Immunology and Immunopathology 37: 334-350, 1985.

20. Szarfman A, Terranova VP, Bernard SI, Foidart JM, Lima MF, Scheinman JI, Martin GR. Antibodies to laminin in Chagas'disease. Journal of Experimental Medicine 155: 1161-1172, 1982.

21. Tafuri WL, Lima Pereira FE, Bobliolo L, Raso P. Lesões do sistema nervoso autônomo e do tecido muscular esquelético na fase crônica da Trypanosoma cruzi experimental. Estudos ao microscópio ótico e eletrônico. Revista Goiana de Medicina 26: 61-65, 1979.

22. Teixeira ARL, Teixeira ML, Santos-Buch CA. The immunology of experimental Chagas'disease. IV. Production of lesions in rabbits similar to those of chronic Chagas'disease in man. American Journal of Pathology 80: 163-178, 1975.

23. Teixeira ARL, Teixeira G, Macedo V, Prata A. Trypanosoma cruzi-sensitized T-lymphocyte-mediate ${ }^{51} \mathrm{Cr}$ release from human cells in Chaga's disease. American Journal of Tropical Medicine and Hygiene 27: 1097-1107,

24. Teixeira ARL, Junqueira LF, Solorzano E, Zappalá M. Doença de Chagas experimental em coelhos isogênicos III/J. I. Fisiopatologia das arritmias e da morte súbita do chagásico. Revista Associação Médica Brasileira 29: 77-89, 1983. 
25. Teixeira ARL. Competência imunológica do paciente chagásico. Imunodepressão na forma aguda inaparente. Auto-imunidade no hospedeiro imunizado. Tese. Faculdade de Medicina da Universidade Federal de Minas Gerais, Belo Horizonte, p. 168, 1981.

26. Teixeira ARL, Teixeira G, Macêdo V, Prata A. Acquired cell-mediated immunity in experimental Chagas'disease. Journal of Clinical Investigation 62: 1132-1143, 1977.
27. Teixeira ARL. The stercorarian trypanosomes. In: The Immunology, Immunopathology and Immunoprophylaxis of Chaga's Disease. Soulsby EJL (ed.), CRC Press, 1987.

28. Wood JN, Hudson L, Jessell TM, Iamamoto M. A monoclonal antibody defining antigenic determinants on subpopulation of mammalian neurones and Trypanosoma cruzi parasites. Nature 296: 3438, 1980. 